\title{
Tinjauan visual pada iklan televisi Kartu As versi Gulai Otak
}

\author{
Winona Octora ${ }^{1}$, Syahril Iskandar ${ }^{2}$ \\ Desain Komunikasi Visual, Universitas Komputer Indonesia \\ Email: ${ }^{1}$ winonaoctora@gmail.com, ${ }^{2}$ syahriliskandar@gmail.com
}

\begin{abstract}
ABSTRAK
Tujuan dari penelitian ini adalah mengungkap makna dibalik visual iklan televisi Kartu As versi Gulai Otak yang mempromosikan salah satu programnya yaitu Paket Kenyang Internetan Mingguan. Menemukan hubungan antara masakan khas Padang dengan paket data internetan. Pada penelitian ini akan digunakan metode penelitian kualitatif dan analisis deskriptif, dengan pembedahan tanda-tanda yang terdapat pada iklan televisi Kartu As versi Gulai Otak dilakukan dengan menggunakan teori semiotika yang dikemukakan oleh Ferdinand de Saussure. Hasil yang didapatkan dari penelitian ini adalah ditemukan adanya upaya pengalihan tanda dari paket internetan melalui jenis dan istilah pada makanan. Seperti paket internet yang memiliki banyak fasilitas dihubungkan dengan banyak jenis makanan khas Padang yang dikenal secara umum dan terjangkau.
\end{abstract}

Kata Kunci : Kartu As, Makna, Pictorial Metaphor, Provider, Semiotika. 


\section{PENDAHULUAN}

Memasarkan suatu produk barang atau jasa meliputi banyak tahapan. Salah satu tahapan terpenting dalam pemasaran yaitu periklanan. Menurut data Nielsen Advertising Information Services yang dirilis Nielsen Indonesia, pada periode Januari-Juni 2016 pengiklan terbesar ketiga adalah perangkat dan layanan komunikasi. Layanan komunikasi di Indonesia salah satunya adalah layanan telekomunikasi seluler yang berbasis jaringan dan transfer data. Penyedia layanan telekomunikasi biasa disebut provider telekomunikasi.

Indonesia merupakan salah satu negara dengan jumlah pengguna telekomunikasi menggunakan telepon seluler terbanyak di dunia sehingga provider telekomunikasi di Indonesia pun terus berlomba dalam memasarkan produknya. Di Indonesia terdapat beberapa provider telekomunikasi diantaranya adalah XL, Indosat, Smartfren, dan Telkomsel. PT. Telekomunikasi Seluler, Tbk. merupakan salah satu perusahaan telekomunikasi terbesar di Indonesia di bawah naungan Telkom Group Indonesia. Saat ini Telkomsel memiliki 4 produk kartu perdana dengan pangsa pasar berbeda yaitu Kartu Halo, Simpati, dan Kartu As.

Kartu As yang dipasarkan untuk pelajar/mahasiswa dan para pekerja muda menyediakan berbagai macam pilihan program paket internet seperti Puas Internetan, Kenyang Internetan, Paket Murah Kartu As, dan masih banyak lagi. Mengikuti perkembangan zaman, internet saat ini merupakan hal yang dibutuhkan semua orang. Untuk mempromosikan programnya tersebut Kartu As melakukan promosi dengan membuat iklan yang dipasang pada beberapa media.
Salah satu program paket internet yang dipromosikan oleh Kartu As adalah Paket Kenyang Internetan Mingguan. Dalam mempromosikan program ini Kartu As membuat sebuah iklan televisi yang berupa iklan reminding (sebagai pengingat). Iklan untuk program Paket Kenyang Internetan Mingguan ini biasa disebut iklan Kartu As versi Gulai Otak. Iklan ini menampilkan suasana pagi di sebuah rumah yang berisi satu keluarga yang disebut Keluarga Asikin yang terdiri dari ayah, ibu, anak laki-laki, dan anak perempuan. Iklan ini menggunakan narasi yang humoris dan menggambarkan kegiatan sehari-hari masyarakat Indonesia yang kekinian, seperti remaja yang selalu memainkan smartphone.

Iklan versi Gulai Otak ini menceritakan tentang ibu yang sedang sakit gigi dan merasa terganggu oleh suara tukang sayur yang sedang menjajakan dagangannya, iklan ini menampilkan hal-hal lucu yang terjadi di dalam keluarga tersebut. Salah satu narasi yang akan terngiang ketika melihat iklan ini adalah sebuah kalimat yang diucapkan oleh anak perempuan di Keluarga Asikin yaitu "Bang, punya otak ga?"

Iklan ini menarik untuk diteliti karena cerita yang ditampilkan memperlihatkan kenyataan dalam kehidupan sehari-hari sehingga konsumen dapat merasakan hal tersebut. Seperti tukang sayur yang selalu berkeliling di pagi hari, sakit gigi yang membuat orang menjadi lebih sensitif, penggunaan internet yang semakin mudah, dan lain sebagainya. Pengaitan hal-hal yang terdapat pada kehidupan sehari-hari dengan paket internet mingguan pada iklan ini, seperti misalnya paket internet yang dikaitkan dengan paket makanan, menjadi salah satu hal yang membuat iklan ini menarik untuk diteliti. Di dalam iklan Kartu As versi Gulai Otak ini terdapat banyak hal 
yang akan menimbulkan pertanyaan bagi pemirsa, utamanya mengenai apa hubungan hal tersebut dengan paket internet mingguan yang diiklankan? Seperti keluarga, sakit gigi, dan makanan.

Salah satu hal yang khas dari iklan ini yaitu warna merah yang mendominasi setting tempat pada iklan Kartu As versi Gulai Otak ini. Pada iklan ini terdapat beberapa scene yang hanya menampilkan gesture tubuh dan mimik wajah para tokoh. Salah satu contohnya adalah sang ibu yang menjawab pertanyaan dari sang ayah tanpa mengucapkan kata-kata melainkan hanya tersenyum sambil tertawa. Dari salah satu dialog yang dikatakan oleh sang ayah yaitu "Gak masak lagi? Sudah seminggu nih..." semakin memicu munculnya pertanyaan seperti apakah maksud dari iklan ini, serta bagaimana bahasa visual televisi yang terdapat pada iklan Kartu As versi Gulai Otak ini, membuat iklan ini semakin menarik untuk diteliti. Belum adanya penelitian pada iklan Kartu As versi Gulai Otak ini juga menjadi urgensi penelitian yang lainnya pada penelitian ini.

\section{TINJAUAN TEORITIK}

Penelitian ini menggunakan pendekatan penelitian kualitatif dan analisis deskriptif yang berarti dilakukan secara sistematis dan faktual berdasarkan data yang ada serta bersifat umum dan dapat berkembang. Masalah dianalisa menggunakan metode analisis deskriptif yang berupa pemaparan dalam bentuk paragraf. Metode pengumpulan data yang dilakukan penulis dalam penelitian ini yaitu studi literatur melalui jurnal, artikel, dan buku-buku yang berkaitan dengan objek penelitian. Instrumen penelitian dilakukan secara subjektif tanpa observasi melalui angket, tes, atau kuesioner, melainkan melalui observasi terhadap tinjauan pustaka dan mengamati objek penelitian yang berupa iklan televisi, yaitu iklan televisi Kartu As versi Gulai Otak dengan judul video Kartu As - Paket Mingguan Bikin Kenyang Internetan yang didapatkan dari akun YouTube resmi Telkomsel.

Kajian pustaka yang penulis lakukan diantaranya memahami teori-teori sebagai berikut:

- Teori semiotika yang dikemukakan oleh Ferdinand de Saussure (1916).

- Teori Pictorial Metaphor yang dikemukakan oleh Charles Forceville (1994).

\section{PEMBAHASAN}

Pada penjualan barang dan jasa terdapat tiga bentuk iklan produk yaitu pioneering (perintisan), competitive (persaingan), dan reminder (pengingatan kembali). Media yang digunakan untuk beriklan diantaranya adalah televisi, majalah, koran, radio, dan outdoor (Shimp, 2003, h.507). Dalam menentukan media pada periklanan tidak bisa sembarangan. Media yang terbaik tergantung pada tujuan pengiklan, kebutuhan kreatif, tantangan persaingan, dan ketersediaan anggaran. Menurut data Nielsen Advertising Information Services yang dirilis Nielsen Indonesia, pada periode Januari-Juni 2016 pengiklan terbesar ketiga adalah perangkat dan layanan komunikasi. Layanan komunikasi di Indonesia salah satunya adalah layanan telekomunikasi seluler. Penyedia layanan telekomunikasi biasa disebut provider telekomunikasi. Indonesia merupakan salah satu negara dengan pengguna telekomunikasi menggunakan telepon seluler terbanyak di dunia sehingga provider telekomunikasi di Indonesia pun terus berlomba dalam 
memasarkan produknya. Termasuk didalamnya adalah Kartu As yang mencoba menarik konsumen di Indonesia melalui pendekatan makanan yang dihubungkan dengan produk yang ditawarkan.

Dari sekian banyak tanda yang terdapat pada iklan Kartu As versi Gulai Otak ini, Paket Makanan Mingguan merupakan tanda yang berkaitan dengan produk yang diiklankan yaitu Paket Kenyang Internetan Mingguan. Paket Kenyang Internetan Mingguan adalah paket yang memiliki banyak fasilitas seperti paket nelpon dan SMS, paket internetan, dan paket video, musik, games, Hello Doctor, dan artis. Paket tersebut memiliki harga yang terjangkau yaitu dimulai dari Rp5000,-. Berikut adalah hasil penelitian terhadap Paket Makanan Mingguan yang telah dilakukan dengan menggunakan teori semiologi Ferdinand de Saussure dengan model sign, signified, signifier.

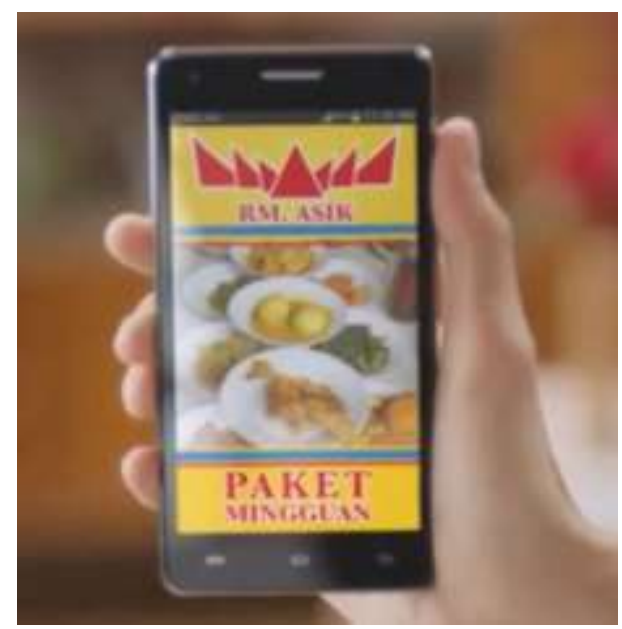

Gambar 1: Iklan paket makanan mingguan Rumah Makan Asik yang dirilis oleh Telkomsel. Sumber Gambar:

https://www.youtube.com/watch?v=8Qn06hGq7x0

Tabel 1:Tabel semiotika pada scene 4: Paket Makanan

\begin{tabular}{|c|l|l|}
\hline \multicolumn{1}{|c|}{ Sign } & \multicolumn{1}{|c|}{ Signifier } & \multicolumn{1}{c|}{ Signified } \\
\hline & $\begin{array}{l}\text { Layar smartphone yang } \\
\text { menampilkan gambar makan serta } \\
\text { tulisan RM. ASIK dan PAKET } \\
\text { MINGGUAN. }\end{array}$ & $\begin{array}{l}\text { Gambar paket makanan mingguan } \\
\text { yang dijual oleh secara online oleh } \\
\text { rumah makan Asik. }\end{array}$ \\
\hline & $\begin{array}{l}\text { Ilustrasi atap Rumah Gadang yang } \\
\text { terletak di atas tulisan RM. ASIK. }\end{array}$ & $\begin{array}{l}\text { Ilustrasi atap Rumah Gadang } \\
\text { digunakan untuk menunjukkan } \\
\text { bahwa rumah makan tersebut } \\
\text { adalah rumah makan Padang. }\end{array}$ \\
\hline & $\begin{array}{l}\text { Gambar beberapa jenis masakan } \\
\text { yang diletakkan pada piring putih } \\
\text { dan disusun secara bertumpuk. }\end{array}$ & $\begin{array}{l}\text { Beberapa jenis masakan padang } \\
\text { yang dihidangkan pada meja dan } \\
\text { disusun secara bertumpuk. }\end{array}$ \\
\hline
\end{tabular}


Setelah membedah tanda-tanda, makna denotatif dan konotatif dari paket makanan yang terdapat pada iklan televisi Kartu As Gulai Otak pun dapat diketahui sebagai berikut:

\section{- Makna Denotatif}

Pada layar smartphone yang ditunjukkan Asrul kepada Bu Astuti, terdapat gambar banyak makanan beserta tulisan RM. ASIK dan PAKET MINGGUAN. Tulisan yang terdapat pada gambar tersebut berwarna merah.

\section{- Makna Konotatif}

Setelah mendengar Pak Asikin kebingungan dan mengeluh karena Bu Astuti tidak akan memasak lagi, Asrul bergegas menunjukkan paket makanan mingguan yang disediakan oleh Rumah Makan Asik. Dilihat dari elemen visual yang terdapat pada iklan paket makanan tersebut, Rumah Makan Asik adalah rumah makan (restoran) yang menyediakan masakan khas Padang (Sumetera Barat) yang menyediakan paket mingguan masakan Padang. Hal ini terlihat dari ilustrasi atap Rumah Gadang yang merupakan rumah tradisional dari daerah Sumatera Barat. Gambar atau ilustrasi atap Rumah Gadang biasanya digunakan pada identitas visual dari rumah makan atau restoran khas Padang. Berikut adalah referensi visual mengenai ilustrasi Rumah Gadang dan contoh atap Rumah Gadang yang menjadi ciri khas dan representasi identitas visual khas kota Padang. Referensi ini diambil sekian banyak tampilan visual yang ada dan merupakan ciri dari salah satu Rumah Makan Padang:

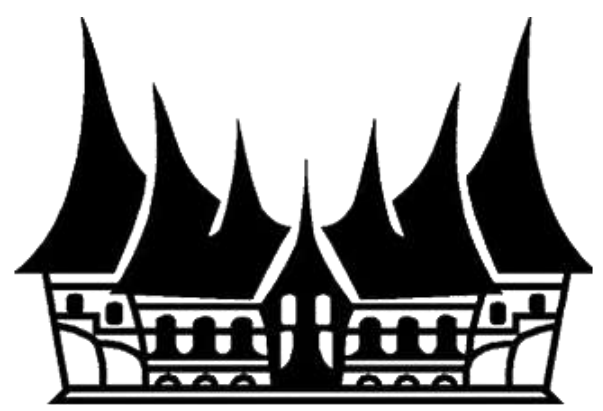

Gambar 2: Ilustrasi rumah Gadang Sumber: http://hdwallpapersbuzz.com/wpcontent/uploads/2017/04/logo-rumah-makanpadang-2.png

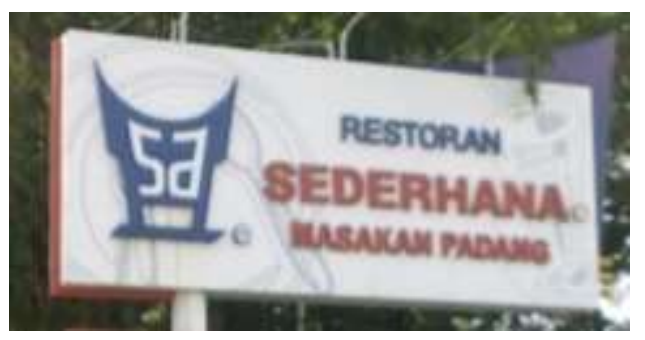

Gambar 3: Identitas visual rumah makan Padang Sumber: http://hariansinggalang.co.id/wpcontent/uploads/2015/09/sederhana.jpg

Selain ilustrasi Rumah Gadang yang menjadi tanda dari rumah makan masakan khas Padang, masakan yang terdapat pada gambar yang ditunjukkan Asrul pun menunjukkan bahwa masakan tersebut adalah memang masakan Padang. Terlihat dari banyaknya jenis makanan yang diletakkan di atas piring berwarna putih, dan disusun secara bertumpuk antara beberapa piring dan piring lainnya. Pada umumnya, restoran Padang menyajikan makanan menggunakan piring berwarna putih, kemudian piring yang berisi makanan diletakkan secara bertumpuk di atas meja. Gulai otak merupakan salah satu makanan Padang yang biasa tersedia di rumah makan Padang. Berikut adalah referensi visual dari penyajian masakan Padang pada umumnya: 


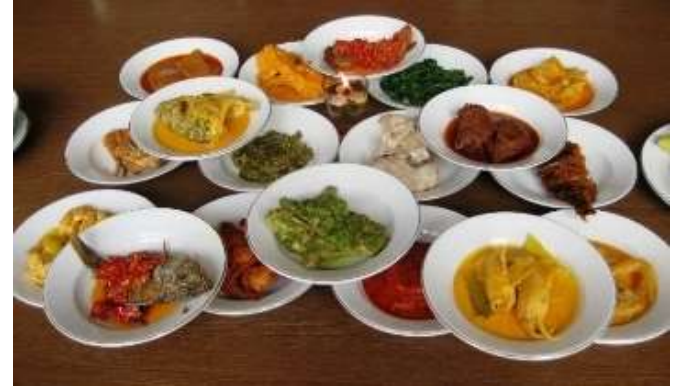

Gambar 4: Cara penyajian masakan khas Padang yang ada di rumah makan atau restoran Padang. Sumber:

http://kooliner.com/blog/wpcontent/uploads/20 17/03/saribundobiz.jpg

Warna merah yang dominan digunakan pada tulisan RM. ASIK dan PAKET MINGGUAN, serta pada ilustrasi atap Rumah Gadang menunjukkan warna khas perusahaan dari Kartu As dan Telkomsel. Selain warna, pada nama RM. ASIK pun kembali disisipkan kata "AS" yaitu tepatnya pada kata "ASik". Penyisipan kata "AS" ini kembali digunakan setelah sebelumnya diketahui bahwa kata "AS" pun disisipkan pada nama-nama lainya yang digunakan pada iklan Kartu As versi Gulai Otak ini seperti pada nama "ASikin" dan yang lainnya.

Kalimat PAKET MINGGUAN yang terdapat pada gambar di smartphone Asrul menunjukkan bahwa paket makanan tersebut merupakan paket makanan mingguan yang menyediakan makanan dengan porsi 1 minggu. Kata mingguan yang terdapat pada kalimat PAKET MINGGUAN pun secara tidak langsung menunjukkan nama produk yang sedang diiklankan oleh iklan televisi Kartu As versi Gulai Otak ini, yaitu Paket Kenyang Internetan Mingguan.

Setelah dilakukan penelitian terhadap makna dari tanda yang terdapat pada iklan televisi Kartu As versi Gulai Otak ini, dapat diketahui bahwa pengiklan menggunakan metafora untuk merepresentasikan produk yang diiklankannya. Pada iklan televisi Kartu
As versi Gulai Otak ini, pengiklan menggunakan Makanan Padang untuk merepresentasikan Paket Kenyang Internetan yang diiklankannya.

Dari tahapan penelitian yang telah dilakukan sebelumnya, dapat ditentukan metafora yang digunakan adalah metafora visual atau Pictorial Metaphor. Metafora merupakan suatu ilmu yang mempelajari tentang merepresentasikan suatu hal menggunakan hal lain dengan maksud dan makna yang serupa. Seperti Lakoff dan Johnson (seperti dikutip Chandler, 2002) yang berdebat bahwa the essence of metaphor is understanding and experiencing one kind of thing in terms of another, yang berarti bahwa esensi atau hakikat dari metafora adalah memahami dan merasakan suatu hal dalam bentuk lain. Dalam bentuk semiotika, metafora melibatkan suatu petanda sebagai penanda yang ditujukan kepada suatu petanda yang berbeda (Chandler, 2002, h.127).

Forceville (2002) menyatakan bahwa terdapat 4 jenis Pictorial Metaphor yang dapat dibedakan tergantung dari sifat bentuk kedua, yaitu subjek sekunder. Berikut adalah jenis-jenis Pictorial Metaphor(h.163):

- Pictorial Metaphor with one pictorially present term (MP1s), adalah Pictorial Metaphor dimana subjek kedua tidak digambarkan atau diperlihatkan, akan tetapi diwakili oleh subjek primer yang merupakan sebuah gambar.

- Pictorial Metaphor with two pictorially present term (MP2s), adalah Pictorial Metaphor yang menghadirkan gambar dari kedua bentuk. 
- Pictorial similes, adalah Pictorial Metaphor yang merepresentasikan kedua bentuk dengan gambar secara keseluruhan.

Verbo-Pictorial Metaphors (VPMs), adalah Pictorial Metaphor yang disajikan secara verbal, yaitu dengan teks yang disajikan.

\section{KESIMPULAN}

Pada penelitian ini diketahui bahwa Pictorial Metaphor yang digunakan pada iklan Kartu As versi Gulai Otak adalah
Pictorial Metaphor with one pictorially present term atau MP1s dimana subjek sekunder tidak ditampilkan karena sudah terwakili oleh subjek primer. Makanan khas Padang pada iklan ini, merupakan poin utama dari iklan ini karena Makanan Padang tersebut merupakan representasi dari Paket Kenyang Internetan yang diiklankan. Untuk meyakinkan bahwa hal tersebut merupakan bentuk metafora, penulis akan melakukan penelitian terhadap subjek primer dan subjek sekunder berdasarkan teori Pictorial Metaphor yang dikemukakan oleh Charles Forceville.

\begin{tabular}{|c|c|}
\hline Subjek Primer & Subjek Sekunder \\
\hline $\begin{aligned} & \text { Paket Makanan Padang Mingguan RM. ASik } \\
& \text { - } \text { Jenis makanan } \\
& \text { - } \text { Mengenyangkan } \\
& \text { - } \text { Memiliki banyak jenis } \\
& \text { - } \text { Harga terjangkau } \\
& \text { - } \text { Salah satu kebutuhan masyarakat } \\
& \text { - } \text { Dijual dalam bentuk paket } \\
& \text { mingguan } \\
& \text { - } \text { Dijual oleh Rumah Makan Asik }\end{aligned}$ & 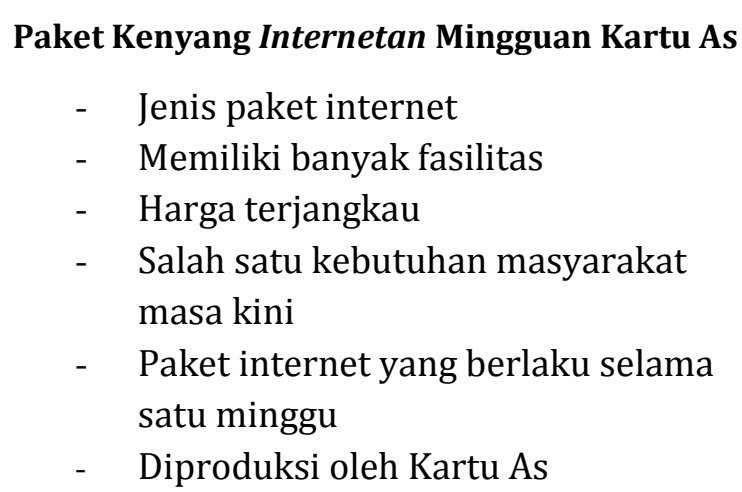 \\
\hline
\end{tabular}

Tabel 2: Subjek Primer dan Subjek Sekunder

Dari tabel di atas dapat terlihat bahwa subjek primer dan subjek sekunder memiliki keterkaitan satu sama lain. Dalam metafora pada iklan ini, terjadi subtitusi antara subjek sekunder dan subjek primer. Subjek sekunder di subtitusi kepada subjek primer untuk membuat ungkapan yang ditampilkan pada iklan ini menjadi lebih menarik. Subjek sekunder yaitu Paket Kenyang Internetan, disubtitusi kepada subjek primer yaitu Paket Makanan Padang Mingguan.
Beberapa jenis makanan Padang tersebut adalah representasi dari beberapa pilihan fasilitas yang terdapat pada Paket Kenyang Internetan Mingguan Kartu As. Paket biasanya dibuat untuk mendapatkan beberapa barang dengan harga yang irit. Paket mingguan berarti paket yang berlaku dalam jangka waktu seminggu. Penggunaan kata "kenyang" pada nama paket internet mingguan yang dihadirkan oleh Kartu As ini adalah salah satu alasan kuat mengapa paket internet ini direpresentasikan melalui makanan. 


\begin{tabular}{|c|c|c|}
\hline Subjek Primer & Subjek Sekunder & Projected Features \\
\hline $\begin{array}{c}\text { Paket Makanan Padang } \\
\text { Mingguan RM. ASik }\end{array}$ & $\begin{array}{c}\text { Paket Kenyang Internertan } \\
\text { Mingguan Kartu As }\end{array}$ & "Mengenyangkan" \\
\hline
\end{tabular}

Tabel 3: Subjek Primer, Subjek Sekunder, dan Projected Features

Dari hasil penelitian di atas, dapat diketahui bahwa projecting features yang terdapat pada metafora yang digunakan pada iklan ini yaitu "mengenyangkan". Penggunaan metafora ini pun menjadi semakin terasa ketika mendengar tagline yang diucapkan oleh narator pada akhir iklan televisi Kartu As versi Gulai Otak ini, yaitu "Kenyang internetan dengan Kartu AS! Lebih irit, pilihannya komplit..". Tagline tersebut telah terwakilkan oleh Bu Astuti yang merasa kenyang dengan mengkonsumsi paket makanan dari Rumah Makan Asik yang terdiri dari banyak menu.

\section{DAFTAR PUSTAKA}

[1] Chandler, Daniel. (2007). Semiotics The Basics. USA dan Kanada: Routledge.

[2] Fanani, Fajriannoor. (2013). Semiotika Strukturalisme Saussure. THE MESSENGER, Volume V, Nomor 1, Edisi Januari 2013. Diambil dari: http://journals.usm.ac.id/index.php/the-messenger/article/viewFile/149/121

[3] Forceville, Charles. (2002). Pictorial Metaphor in Metaphor. USA dan Kanada: Routledge.

[4] Sobur, Alex. (2013). Semiotika Komunikasi. Bandung: PT. Remaja Rosdakarya.

[5] Rayya, Helfina. Telaah Konsep Semiotik Ferdinand de Saussure. Tersedia di: http://www.academia.edu 